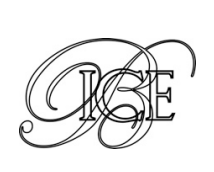

\author{
Almudena López-Manterola *
}

\title{
LOS NUEVOS CANDIDATOS A LA UNIÓN EUROPEA: ESTADO DE SITUACIÓN
}

La Unión Europea se ha ido ampliando desde los 6 países fundadores de la Comunidad Económica Europea en 1958 hasta los 28 actuales a través de 8 ampliaciones. En la actualidad, hay cinco países que tienen la categoría oficial de candidatos (Turquía, la Antigua República Yugoslava de Macedonia, Montenegro, Serbia y Albania) y un candidato potencial (Bosnia y Herzegovina). En el artículo se repasan los criterios que un país tiene que cumplir para poder adherirse y el estado de situación de cada país en este proceso, las ayudas a su disposición, así como sus relaciones comerciales con la Unión. En cualquier caso, todo indica que puede descartarse una nueva ampliación antes de 2020.

Palabras clave: países candidatos, relaciones comerciales, Acuerdos de Asociación.

Clasificación JEL: F10, F50, F59.

\section{Introducción}

La primera ampliación de la entonces denominada Comunidad Económica Europea (CEE) tuvo lugar 15 años después de su fundación en 1958 por sus 6 miembros fundadores: Bélgica, RF de Alemania, Francia, Italia, Luxemburgo y los Países Bajos. En 1973 se incorporaron Reino Unido, Irlanda y Dinamarca (incluida Groenlandia). Croacia fue la última incorporación en 2013. En esos 40 años la hoy Unión Europea (UE) ha realizado 6 ampliaciones más, a intervalos siempre inferiores a 10 años, hasta alcanzar su configuración actual de 28 Estados miembros (EEMM).

En este camino, algunos países decidieron no seguir adelante con su adhesión, como Noruega que decidió retirar su solicitud o Suiza e Islandia que han congelado sus procesos de adhesión.

\footnotetext{
* Subdirección General de Política Comercial con Europa, Asia y Oceanía.

Versión de mayo de 2015.
}

Otros incluso decidieron marcharse, como fue el caso de Groenlandia en 1985. Algunos como Turquía llevan años de difíciles negociaciones.

La caída del Muro de Berlín en 1989 supuso el comienzo de un proceso de ampliación e integración europea sin precedentes en el que la UE se abrió hacia el centro y este de Europa, expresando nuevamente su vocación de acoger a todos los países del continente que así lo deseen y que cumplan unos criterios políticos y económicos sine quanon.

Como consecuencia de este proceso, en mayo de 2004 se produjo la ampliación más numerosa de su historia, con la adhesión simultánea de 10 países (Polonia, República Checa, Eslovaquia, Hungría, Eslovenia, Estonia, Letonia, Lituania, Malta y Chipre). Rumania y Bulgaria se incorporaron en 2007.

El proceso de ampliación actualmente en marcha se centra en los Balcanes Occidentales y Turquía. Tienen ya estatus oficial de países candidatos Turquía (1999), la Antigua República Yugoslava de Macedonia (2005), Montenegro (2010), $\triangleright$ 
Serbia (2012) y Albania (2014). Son candidatos potenciales Bosnia y Herzegovina y el territorio de Kosovo, cuyo estatus como país no ha sido reconocido por cinco EEMM, entre ellos España.

En un futuro no demasiado lejano todos los países surgidos tras la disolución de la República Federal Socialista de Yugoslavia podrían pasar a ser miembros de la UE.

\section{Criterios para la adhesión}

El Tratado de la Unión Europea establece que cualquier país europeo puede solicitar ser miembro de la misma si respeta los valores democráticos que presiden la UE y se compromete en la defensa de los mismos. Para poder llegar a ser Estado miembro de la UE debe cumplir con sus normas y reglas, contar con el consentimiento de las instituciones comunitarias y del resto de los EEMM y contar con el consentimiento de sus propios ciudadanos expresado como proceda según su legislación nacional, esto es, mediante aprobación del Parlamento o mediante referéndum.

Los primeros pasos hacia la adhesión se rigen por los denominados criterios de Copenhague ${ }^{1}$ (Consejo Europeo de 1993). Los países que deseen entrar en la UE deben de tener:

- Un marco institucional estable que garantice la democracia, el estado de derecho, los derechos humanos y el respeto y protección de las minorías.

- Una economía de mercado con capacidad para asumir la competencia y las fuerzas de mercado de la UE.

- La capacidad de asumir y ejecutar de manera efectiva las obligaciones de la membresía, incluyendo los objetivos de la unión política, económica y monetaria.

En el caso de los Balcanes Occidentales, se han establecido además unas condiciones adicionales en el denominado «Proceso de estabilización y 1993. asociación» que se refieren fundamentalmente a la cooperación regional y a las buenas relaciones de vecindad. Este acuerdo prevé la liberalización de los flujos bilaterales de comercio y de inversión, refuerza la integración económica entre las partes y apoya la gradual aproximación de los países en cuestión a los requerimientos del mercado interior de la Unión Europea.

A partir del año 2000 la UE fue firmando con cada uno de los países balcánicos un Acuerdo de Estabilización y Asociación (AEA) que proporciona el marco legal completo para las relaciones entre las partes con tres focos fundamentales: diálogo político, aproximación de legislaciones y desarrollo paulatino de una zona de libre comercio.

El objetivo del proceso de asociación, en el que también está incluida Turquía desde la firma de su Acuerdo de Asociación en 1963, es actualmente preparar a los países para su acceso a la UE. Una vez cumplidos por el país candidato los criterios de adhesión y obtenido el consentimiento de los EEMM y las instituciones comunitarias, se abre el proceso de negociación en el que las partes deben negociar las condiciones y el programa de adopción y aplicación de todo el acervo comunitario en vigor, que a tal efecto se ha dividido en 35 capítulos que se negocian separadamente.

\section{Financiación preadhesión}

Hasta el 1 de enero de 2007 la asistencia preadhesión de la UE a los países candidatos se prestaba a través de distintos instrumentos financieros:

- El programa PHARE financiaba medidas destinadas al fortalecimiento institucional, la cohesión económica y social y la cooperación transfronteriza.

- El programa ISPA financiaba grandes infraestructuras de transporte y medio ambiente.

- El programa SAPARD financiaba la agricultura y el desarrollo regional.

- El programa CARDS era el instrumento financiero para apoyar el proceso de estabilización y asociación en los Balcanes Occidentales. 


\begin{tabular}{|c|c|c|c|c|c|c|}
\hline \multicolumn{7}{|c|}{$\begin{array}{c}\text { TABLA } 1 \\
\text { IPA II 2014-2020 ASIGNACIONES INDICATIVAS }\end{array}$} \\
\hline País & 2014 & 2015 & 2016 & 2017 & 2018-2020 & Total 2014-2020 \\
\hline Albania & 83,7 & 86,9 & 89,7 & 92,9 & 296,3 & 649.5 \\
\hline 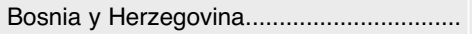 & 39,7 & 39,7 & 42,7 & 43,7 & * & 165.8 \\
\hline ARY Macedonia ........................................ & 85,7 & 88,9 & 91,6 & 94,9 & 303,1 & 664.2 \\
\hline Territorio de Kosovo ...................................... & 83,8 & 85,9 & 88,7 & 91,9 & 295,2 & 645.5 \\
\hline 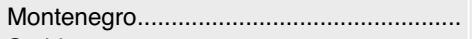 & 39,6 & 35,6 & 37,4 & 39,5 & 118,4 & 270.5 \\
\hline Serbia & 195,1 & 201,4 & 207,9 & 215,4 & 688,2 & $1.508,0$ \\
\hline 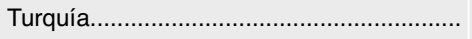 & 620,4 & 626,4 & 630,7 & 636,4 & $1.940,0$ & $4.453,9$ \\
\hline 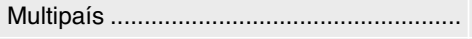 & 348,0 & 365,0 & 390,0 & 410,4 & $1.445,3$ & $2.958,7$ \\
\hline
\end{tabular}

- Turquía también recibía ayuda financiera preadhesión a través de instrumentos, líneas de crédito y procedimientos similares pero separados, siendo el más importante de ellos el Instrumento de Preadhesión de Turquía.

El 1 de enero de 2007 desaparecieron todos estos instrumentos en favor del nuevo Instrumento de Asistencia Preadhesión (IAP) creado por la UE específicamente para proporcionar asistencia financiera y técnica a todos los países candidatos y candidatos potenciales. Mantiene el énfasis en el fortalecimiento institucional para que los países puedan llevar a cabo las reformas necesarias para la adaptación a las normas y al acervo UE. En el primer periodo presupuestario 2007-2013 IAP contó con 11,5 mil millones de euros. El IAP $\|^{2}$ dedicará una cantidad similar, 11,7 mil millones de euros, para el periodo 2014-2020.

EI IAP financia proyectos en cinco áreas de actuación:

- Componente I - Ayuda a la transición y desarrollo institucional.

- Componente II - Cooperación transfronteriza.

- Componente III - Desarrollo regional.

- Componente IV - Desarrollo de recursos humanos.

- Componente V - Desarrollo rural.

Los fondos destinados a todos los componentes, excepto los correspondientes al componente II, se pueden gestionar de manera descentralizada por las autoridades nacionales de cada uno de los países candidatos.

2 Regulation (EU) No 231/2014 of the European Parliament and of the Council of 11 march 2014 establishing an Instrument for Preaccession Assistance (IPA II).
La principal novedad del IAP II es su enfoque estratégico en sectores prioritarios y en el cumplimento de los países beneficiarios en la ejecución de las reformas necesarias para su acceso a la UE. Para cada uno de los países beneficiarios se elabora un documento estratégico que abarca un periodo de 7 años e identifica sus necesidades específicas. De ellos se derivarán después los programas de acción para cada uno de los países, anuales o plurianuales, los programas de acción multipaís, los programas de cooperación transfronteriza y los programas de desarrollo rural.

EI IAP II sólo financiará proyectos maduros con un enfoque sectorial, en aquellos sectores más relacionados con la estrategia de adhesión, concretamente en democracia y estado de derecho y en crecimiento y competitividad. La Tabla 1 muestra las asignaciones indicativas de fondos IAP II para cada uno de los países candidatos en el periodo 2014-2020.

Los sectores prioritarios de financiación durante este periodo serán:

- Democracia y gobernabilidad.

- Estado de derecho y derechos fundamentales.

- Medio ambiente, transporte y energía.

- Competitividad e innovación.

- Educación, empleo y políticas sociales.

- Agricultura y desarrollo rural.

- Cooperación regional y territorial.

\section{Países candidatos}

Analizaremos a continuación cada uno de los actuales países candidatos en el orden de aceptación de sus candidaturas. 


\subsection{Turquía}

En 1959 Turquía fue uno de los primeros países en mostrar interés por cooperar estrechamente con la joven CEE. Estos deseos de cooperación se materializaron en 1963 con la firma de un Acuerdo de Asociación conocido como el Acuerdo de Ankara cuyo objetivo principal era conseguir la mejora de las condiciones de vida en Turquía, acelerar su crecimiento económico, conseguir un crecimiento armonioso del comercio y disminuir las disparidades entre la economía turca y la de los países miembros de la CEE.

El Acuerdo de Ankara incluía el establecimiento paulatino de una unión aduanera que permitiría el comercio de Turquía de bienes y productos agrícolas con los países de la CEE sin restricciones. Finalmente la unión aduanera entre la UE actual y Turquía entró en vigor el 1 de enero de 1996. Abarca todos los productos industriales, exceptuando el carbón y el acero, para los que existe un acuerdo específico firmado en 1996. Para los productos agrícolas existen tan solo determinadas concesiones recíprocas.

Turquía es el país candidato que más tiempo lleva negociando su adhesión. Presentó su solicitud a la entonces CEE en 1987 pero no fue hasta la cumbre de Helsinki de 1999 cuando finalmente la UE le concedió el estatus oficial de país candidato. El proceso de ampliación experimentó un importante paso adelante con la apertura de las negociaciones de adhesión el 3 de octubre de 2005.

En junio de 2006 se abrió y cerró provisionalmente el capítulo 25: ciencia e investigación. Sin embargo desde entonces las negociaciones avanzan muy lentamente. En noviembre de 2006 la UE manifestó su preocupación por las restricciones a la libre circulación de mercancías que Turquía estaba aplicando a Chipre, incumpliendo los compromisos adquiridos en 1970 con la firma del Protocolo adicional ${ }^{3}$ del Acuerdo de Ankara.

\footnotetext{
${ }^{3}$ Protocolo adicional y Protocolo financiero, firmados el 23 de noviembre de 1970, anejos al Acuerdo por el que se crea una asociación entre la Comunidad Económica Europea y Turquía y relativo a las medidas que deben adoptarse para su entrada en vigor - Acta final - Declaraciones.
}

Por este motivo, desde diciembre de 2006 y hasta que Turquía acepte aplicar el Protocolo adicional también a Chipre, la negociación de $8 \mathrm{ca}$ pítulos de especial relevancia está suspendida: Capítulo 1: libre circulación de mercancías, Capítulo 3: derecho de establecimiento y libre circulación de servicios, Capítulo 9: servicios financieros, Capítulo 11: agricultura y desarrollo rural, Capítulo 13: pesca, Capítulo 14: política de transporte, Capítulo 29: unión aduanera y Capítulo 30: relaciones exteriores. Además se acordó no cerrar provisionalmente ninguno de los capítulos que se abran hasta que Turquía no cumpla con sus compromisos adquiridos en el Acuerdo de Ankara.

El proceso negociador como tal no fue bloqueado y a partir de 2007 continuó abriéndose la negociación de los capítulos no suspendidos. Hasta un total de 14 capítulos están en negociación. El último en abrirse fue el Capítulo 22: política regional, en noviembre de 2013, tras tres años de bloqueo de las negociaciones, tanto por Francia como por Alemania, que finalmente fue levantado. Se espera que tres nuevos capítulos sean abiertos si Turquía cumple los requisitos técnicos: competencia, compras públicas y política social y empleo.

Pero las reticencias de países como Francia y Alemania y muy especialmente la actitud frontalmente opuesta de Grecia y Chipre a la adhesión de Turquía, que sigue manteniendo una actitud beligerante respecto a la cuestión chipriota, hacen que los avances sean muy lentos.

\section{Asistencia financiera preadhesión}

Turquía ha recibido asistencia preadhesión desde 2001 a través del denominado Instrumento de Preadhesión de Turquía, que fue sustituido en 2007 por el IAP. Con 4.830 millones de euros Turquía es el país candidato que más fondos IAP recibió en el periodo 2007-2013. A través de sus cinco componentes IAP ha seguido proporcionando apoyo financiero a Turquía como lo hacía el instrumento anterior. La novedad de IAP es que introduce apoyo financiero en nuevas áreas como $D$ 
medio ambiente, transporte, competitividad regional, desarrollo de recursos humanos y desarrollo rural. Los fondos se programan por sectores en el marco de programas nacionales anuales.

En $2013^{4}$ el proceso cobró un nuevo impulso con la apertura de negociaciones de un nuevo capítulo. A pesar de las turbulencias políticas, el impacto sobre el proceso de programación se mantuvo controlado y la labor sobre el nuevo Documento de Estrategia prosiguió según lo previsto en el marco financiero plurianual de 2014-2020. Además se delegaron nuevas competencias a las autoridades turcas dentro del régimen de gestión descentralizada. No obstante, en lo que respecta a la ejecución de los programas en el marco del IAP I, se han experimentado retrasos persistentes debido a la capacidad insuficiente de algunas estructuras operativas y de los beneficiarios finales, entre otras cosas.

La asignación indicativa de IAP II para Turquía en el periodo $2014-2020$ es de $4.453,9$ millones de euros.

\subsection{ARY de Macedonia}

La República de Macedonia se declaró independiente de la República Federal Socialista de Yugoslavia en 1991. Grecia rechazó desde el principio esta denominación basándose en motivos históricos y geográficos y el conflicto perdura hasta nuestros días. En 1993 ambos países alcanzaron un compromiso para que el nuevo Estado fuera reconocido oficialmente por Naciones Unidas como Antigua República Yugoslava de Macedonia (ARYM), denominación empleada también en la UE.

El 9 de abril de 2001 se firmó el AEA entre la UE y la ARY Macedonia, que no entró en vigor hasta el 1 de abril de 2004. Junto con el AEA, la ARY Macedonia y la UE firmaron un Acuerdo interino sobre comercio y asuntos relacionados que entró

\footnotetext{
${ }^{4}$ Informe anual de 2013 sobre la ayuda financiera para la ampliación (IAP, PHARE, CARDS, Instrumento de Preadhesión de Turquía, Mecanismo de Transición SWD(2014) 287 final.
}

en vigor en 2001 para permitir la aplicación de la parte comercial del AEA mientras éste seguía su proceso de ratificación por cada uno de los EEMM.

La ARY Macedonia solicitó formalmente su adhesión a la UE en marzo de 2004 y el Consejo Europeo le otorgó oficialmente el estatus de país candidato en diciembre de 2005. A pesar de que en octubre de 2009 la Comisión recomendó iniciar las negociaciones con el nuevo país candidato, a fecha de hoy no han podido comenzar debido al veto griego.

La situación política en la ARY Macedonia presenta una gran complejidad por su situación geográfica y el difícil equilibrio entre los dos grupos étnicos principales (macedonios y albaneses). Las expectativas de apertura de negociaciones para la adhesión a la UE, de ingreso en la OTAN y la supervisión de la economía por parte del FMI han sido los motores del progreso macedonio.

Sin embargo, en junio de 2014 Grecia bloqueó por quinto año consecutivo el inicio de las negociaciones de adhesión a la UE. Grecia considera que el nombre Macedonia pertenece en exclusiva a la tradición helena y que su uso por el país vecino podría suponer pretensiones territoriales hacia la región griega del mismo nombre. Mantiene además bloqueado el ingreso de la ARY Macedonia en la OTAN por el mismo motivo, a pesar de que el Tribunal de la Haya declaró en 2012 que su actuación no se ajusta a los acuerdos entre el país heleno y el país balcánico de 1995.

ARY Macedonia mantiene también un conflicto con Bulgaria por acusaciones mutuas de «apropiación indebida» de la historia común. Por ello, en 2012 Bulgaria se sumó al bloqueo de las negociaciones exigiendo tres condiciones para levantarlo: la firma de un acuerdo bilateral, el establecimiento de sesiones conjuntas de ambos Gobiernos y la conmemoración conjunta de personajes y hechos históricos comunes.

\section{Asistencia financiera preadhesión}

Los fondos recibidos por ARY Macedonia entre 1992 y 2007 a través fundamentalmente de $D$ 
PHARE y CARDS ascendieron a 800 millones de euros. Desde 2007 la asistencia financiera y técnica de la UE a través del instrumento preadhesión IAP se centró en proyectos relacionados con la reforma de la Administración Pública, Justicia, Interior y derechos humanos, desarrollo del sector privado, agricultura y desarrollo rural, transporte, medio ambiente y cambio climático y desarrollo social.

Para el periodo $2007-2013^{5}$ ARY Macedonia tenía asignados 622,4 millones de euros. Durante todo el periodo el sistema de gestión descentralizada de ARY Macedonia presentó algunos cuellos de botella debidos a falta de personal e insuficiente capacidad de gestión de instituciones clave, por lo que algunos fondos no pudieron llegar a comprometerse.

La asignación indicativa de IAP II para ARY Macedonia durante el periodo 2014-2020 es de 664,2 millones de euros.

\subsection{Montenegro}

En mayo de 2006 el Parlamento de Montenegro declaró su independencia del anterior Estado de Serbia y Montenegro, que como tal había comenzado en 2005 sus negociaciones con la UE para el Proceso de Estabilización y Asociación. En septiembre de 2006 Montenegro continuó por separado sus negociaciones con la UE hasta llegar a la firma del AEA en octubre de 2007, que no entró en vigor hasta mayo de 2010. Como todos los AEA, este acuerdo supone una profundización de las relaciones económicas con la UE al no limitarse al establecimiento de concesiones comerciales sino además imponer obligaciones de armonización del mercado montenegrino con las normas del mercado interior europeo.

Junto con el AEA Montenegro y la UE firmaron un Acuerdo interino sobre comercio y asuntos relacionados que entró en vigor en enero de 2008.

\footnotetext{
${ }^{5}$ Informe anual de 2013 sobre la ayuda financiera para la ampliación (IAP, PHARE, CARDS, Instrumento de Preadhesión de Turquía, Mecanismo de Transición SWD(2014) 287 final.
}

El objetivo de este acuerdo era crear una zona de libre comercio entre las partes en un plazo de cinco años a partir de la entrada en vigor del mismo. Transcurridos los periodos transitorios, el Acuerdo interino ha permitido la plena liberalización del comercio bilateral desde el 1 de enero de 2013. Estos dos acuerdos han tenido un papel fundamental en la normalización de las relaciones internacionales de Montenegro, así como en formalizar el apoyo de la UE a su integración en la economía internacional.

Montenegro solicitó su adhesión a la UE en diciembre de 2008 y en diciembre de 2010 la Unión, considerando sus avances en la consolidación de instituciones democráticas y en el desarrollo de una economía de mercado, le concedió oficialmente el estatus de país candidato. Las negociaciones de adhesión se iniciaron formalmente el 29 de junio de 2012 con la celebración de la primera Conferencia Intergubernamental.

A 30 de marzo de 2015 se han abierto 18 de los 35 capítulos de negociación, entre ellos el Capítulo 7: propiedad intelectual, el Capítulo 4: libre circulación de capitales, el Capítulo 32: control financiero y el Capítulo 29: unión aduanera. Los últimos en ser abiertos han sido el Capítulo 16: fiscalidad y el Capítulo 30: relaciones exteriores. Dos capítulos han sido ya cerrados provisionalmente: el Capítulo 25: ciencia e investigación y el Capítulo 26: educación y cultura.

A pesar de ser el país de los Balcanes que se incorporó más tarde al proceso de asociación, Montenegro es el candidato que tiene más avanzadas sus negociaciones de adhesión. Está adoptando el acervo con relativa celeridad, aunque su Administración tiene una capacidad limitada para seguir los últimos desarrollos del mismo. Es posible que se encuentre en situación de ingresar en la UE alrededor de 2020, en contraste con los menores avances de los otros países de la zona.

\section{Asistencia financiera preadhesión}

Montenegro ha estado recibiendo ayuda financiera de la UE desde 1998. La asistencia financiera recibida del programa CARDS entre 1998 y $2007 \triangleright$ 
ascendió a 277, 2 millones de euros. IAP le proporcionó apoyo financiero por valor de 235,7 millones de euros entre 2007 y 2013 . Esta ayuda se está utilizando para realizar reformas en la Administración Pública, el sistema judicial, las infraestructuras, el sector agrario y el energético, entre otros.

Durante $2013^{6}$, Montenegro realizó esfuerzos significativos en el proceso de delegación de competencias de gestión para la ejecución descentralizada de los fondos del IAP. Se relizaron auditorías en todos los componentes salvo el Componente V.

Los preparativos para el IAP II con las autoridades montenegrinas cobraron impulso en el segundo semestre de 2013. Estos preparativos se centraron en la introducción del enfoque sectorial y en el Documento de Estrategia. Al mismo tiempo el país contribuyó al Documento de Estrategia Plurinacional para el IAP II y a la finalización de la Estrategia 2020 para Europa sudoriental, al igual que los demás países de los Balcanes Occidentales.

IPA II ha asignado indicativamente $270,5 \mathrm{mi}-$ llones de euros a Montenegro para el periodo 2014-2020.

\subsection{Serbia}

La República de Serbia y Montenegro fue identificada como país candidato potencial junto con otros 5 países de los Balcanes Occidentales en la cumbre de Tesalónica de 2003. Los conflictos en los Balcanes y el posterior aislamiento internacional de Serbia retrasaron sus acuerdos de cooperación económica con la UE en relación con otros países de la región.

En 2005 comenzó la negociación del AEA como Serbia y Montenegro y la terminó 3 años después como República de Serbia. El AEA fue firmado el 29 de abril de 2008. Como es habitual, simultáneamente se firmó el Acuerdo interino sobre

\footnotetext{
${ }^{6}$ Informe anual de 2013 sobre la ayuda financiera para la ampliación (IAP, PHARE, CARDS, Instrumento de Preadhesión de Turquía, Mecanismo de Transición SWD(2014) 287 final.
}

comercio y asuntos relacionados que permitiría la aplicación de las disposiciones comerciales del AEA.

El proceso de liberalización comercial había comenzado en 2000 con la aplicación unilateral por parte de la UE de un régimen de concesiones que era el más amplio que hasta la fecha había otorgado la UE a ningún país o grupo de países. La UE abolió inmediatamente todos los derechos de aduanas y contingentes para la importación de todos los productos industriales y agrícolas, salvo para un pequeño grupo de estos últimos al que se aplicaron derechos preferenciales.

Por parte de Serbia, la reducción de los derechos de importación para productos originarios en la UE no comenzó hasta 2009, cuando Serbia decidió voluntariamente comenzar a aplicar el Acuerdo interino. Tras expirar todos los periodos transitorios, el 1 de enero de 2014 se produjo la plena liberalización del comercio bilateral entre las partes. Sólo se mantienen algunos derechos para los productos agrícolas más sensibles para Serbia (carnes, algunos lácteos y algunas verduras).

El AEA encontró más problemas para su ratificación. Sufrió un importante retraso en el Consejo debido al bloqueo de algunos EEMM que denunciaban falta de cooperación de Serbia con el Tribunal Penal Internacional para la antigua Yugoslavia. Solventado este problema, la UE decidió el 4 de junio de 2010 dar luz verde al proceso de ratificación de los EEMM, siendo España el primero en ratificarlo el 21 de junio de 2010 y Lituania el último el 18 de junio de 2013. El Acuerdo pudo entrar finalmente en vigor el 1 de septiembre de 2013. Como en el caso de Montenegro, tanto el AEA como el Acuerdo interino han tenido un papel fundamental en la normalización de las relaciones internacionales de Serbia.

Mientras se producían estos complicados procesos, Serbia presentó oficialmente su solicitud de adhesión en diciembre de 2009. En marzo de 2012 la Unión, considerando los avances de Serbia en el diálogo técnico sobre Kosovo ${ }^{7}$ con las autoridades $\triangleright$

\footnotetext{
${ }^{7}$ Esta denominación se entiende sin perjuicio de las posiciones sobre su estatuto y está en consonancia con la Resolución 1244 (1999) del Consejo de Seguridad de las Naciones Unidas y con la Opinión de la Corte Internacional de Justicia sobre la declaración de independencia de Kosovo.
} 
de Pristina, y en especial los acuerdos sobre gestión de límites y representación de Kosovo en foros regionales, le concedió el estatuto de país candidato a la adhesión. En diciembre de 2013 el Consejo aprobó el marco negociador y en enero de 2014 se consideraron formalmente abiertas las negociaciones de adhesión durante la celebración de la primera Conferencia Intergubernamental.

El Gobierno serbio se ha marcado públicamente el objetivo de culminar las negociaciones en 2018 para acceder a la UE en 2020 , pero al ritmo actual de trabajo esta meta podría considerarse poco realista ya que aún no se ha abierto ningún capítulo.

\section{Asistencia financiera preadhesión}

Con 2,6 mil millones de euros hasta 2013, Serbia es uno de los mayores receptores de fondos europeos del mundo y el mayor receptor de la región de los Balcanes Occidentales. Desde la entrada en vigor del IAP en enero de 2007 ha recibido 200 millones de euros anuales que se han utilizado para realizar reformas en la Administración, en el sistema judicial, en las infraestructuras, en el sector agrario y en el energético, entre otros.

Durante $2013^{8}$ se fue preparando activamente el IPA II y el sistema de ejecución descentralizada que empezó a utilizar Serbia a partir de 2014. La asunción de responsabilidades de los organismos nacionales en el proceso de programación del IAP siguió mejorando, especialmente en lo que respecta a la coordinación de los donantes. Pero las autoridades aún tienen que crear unas estructuras institucionales y legales que permitan absorber de manera eficiente y efectiva tanto los fondos de la UE como del resto de los donantes, especialmente en proyectos de infraestructuras.

La asignación indicativa de IPA II para Serbia en el periodo $2014-2010$ es de 1,5 mil millones de euros.

\footnotetext{
${ }^{8}$ Informe anual de 2013 sobre la ayuda financiera para la ampliación (IAP, PHARE, CARDS, Instrumento de Preadhesión de Turquía, Mecanismo de Transición SWD(2014) 287 final.
}

\section{Kosovo}

El territorio de Kosovo ha sido considerado históricamente como la cuna del pueblo serbio, aunque en la actualidad su población es mayoritariamente albanesa. El estatuto internacional de este territorio de Serbia se encuentra en disputa y es uno de los principales escollos para la adhesión de Serbia a la UE. Tras una historia de conflictos, en 1999 Kosovo quedó bajo administración de Naciones Unidas (UNMIK) y de la misión EULEX de la UE, en virtud de la Resolución 1244 (1999) del Consejo de Seguridad de Naciones Unidas.

El 17 de febrero de 2008 las autoridades kosovares declararon de manera unilateral la independencia de su territorio y la constitución de la República de Kosovo, que Serbia no reconoce. Además de Serbia, hay cinco EEMM que no reconocen la declaración de independencia de Kosovo: España, Grecia, Chipre, Eslovaquia y Rumanía. En los Balcanes Occidentales tampoco Bosnia y Herzegovina ha reconocido la independencia de Kosovo.

En octubre de 2012, la Comisión hizo público su estudio de viabilidad sobre las posibilidades de negociación de un AEA con Kosovo, sin perjuicio de la posición de algunos EEMM sobre su estatuto.

En el marco del diálogo facilitado por la UE y después de 10 rondas fallidas de conversaciones, el 19 de abril de 2013 los representantes de Serbia y de Kosovo firmaron en Bruselas un acuerdo histórico que supone el primer paso para la normalización de las relaciones entre ambos territorios, aunque no se pronuncia sobre el estatuto de la provincia en relación con Serbia.

En junio de 2013 el Consejo autorizó a la Comisión a iniciar las negociaciones de un AEA con Kosovo pero sólo en las materias cuya competencia es exclusiva de la UE y que, por tanto, puede firmar y aplicar la Comisión. Se intenta así concluir un acuerdo que respete la posición de todos los EEMM con respecto al estatuto de Kosovo.

Después de varias rondas de negociaciones, en julio de 2014 ambas partes inicializaron el $\triangleright$ 
borrador de texto del AEA y sus correspondientes anexos, que ahora continúan su tramitación interna dentro de las instituciones de la UE hasta la firma oficial por las partes. El AEA pretende promover la cooperación regional y proporcionar la base de una cooperación más amplia. Uno de sus principales objetivos es la profundización en las relaciones económicas y comerciales con miras hacia una futura zona de libre comercio de bienes y servicios.

En el AEA Kosovo se compromete a trabajar para la normalización de sus relaciones con Serbia. En el Capítulo 35: varios, de las negaciones de adhesión con Serbia, está incluida la normalización de relaciones y la resolución del estatuto de Kosovo.

Kosovo recibirá asistencia técnica y financiera de la UE a través del IAP necesaria para poder poner en marcha ciertos aspectos del AEA. La asignación indicativa de IAP II para el periodo 2014-2020 es de 645,5 millones de euros.

\subsection{Albania}

Albania fue uno de los países de los Balcanes Occidentales identificado en la cumbre de Tesalónica de 2003 como candidato potencial a la adhesión. En junio de 2006 firmó el AEA y el Acuerdo interino sobre comercio y asuntos relacionados, que entró en vigor el 1 de abril de 2009. Unos días después Albania presentó oficialmente su solicitud de adhesión. En octubre de 2010 la Comisión consideró que, antes de poder abrir formalmente las negociaciones, Albania tenía que mejorar sus niveles de cumplimiento de los criterios de adhesión y en especial las cinco prioridades clave contenidas en su Opinión de noviembre de $2010^{9}$.

En 2013 la Comisión recomendó oficialmente la concesión de estatus de país candidato siempre que cumpliera una serie de medidas clave en el campo de las reformas administrativa y judicial.

\footnotetext{
${ }^{9}$ Commission Opinion on Albania's application for membership of the European Union $\{$ SEC(2010) 1335\}.
}

Tras considerar el informe ${ }^{10}$ de la Comisión relativo a los avances de Albania en la reforma judicial y en la lucha contra la delincuencia organizada y la corrupción, finalmente el Consejo Europeo de junio de 2014 acordó concederle oficialmente el estatus de país candidato.

Las estructuras del AEA han permitido mantener un diálogo continuo entre la UE y Albania, que en general ha cumplido correctamente con sus obligaciones dentro del AEA.

Sin embargo, los problemas persisten y Albania tiene aún un camino que recorrer en el cumplimiento de las cinco prioridades clave. Esto ha impedido que las instituciones comunitarias den luz verde al comienzo de las negociaciones de adhesión. Sus principales retos siguen siendo acabar con la delincuencia organizada y la corrupción y mejorar el sistema judicial. También será muy importante su posicionamiento en el caso de Kosovo, ya que la mayoría étnica de Kosovo es albanesa.

El 23 y 24 de marzo pasados el Comisario de Ampliación y el Primer Ministro albanés presidieron la V Conferencia de alto nivel UE-Albania en Tirana. En su declaración a la prensa posterior a la reunión, el Comisario Hahn volvió a insistir en algunas de las actuaciones necesarias para que se puedan abrir las negociaciones con Albania:

- Es importante que Albania realice una reforma judicial amplia, incluyente y coherente que aumente la confianza pública en el sistema judicial.

- Es necesaria una política seria y coherente de lucha contra la delincuencia organizada y la corrupción.

- Es esencial seguir mejorando la eficiencia e independencia de la Administración Pública.

\section{Asistencia financiera preadhesión}

Entre 2007 y 2013 Albania recibió aproximadamente 594 millones de euros del IAP para el reforzamiento de la capacidad administrativa de las instituciones y cooperación transfronteriza, todo ello encaminado a fomentar el desarrollo social, medioambiental y económico.

\footnotetext{
${ }^{10}$ Albania's Progress in the Fight Against Corruption and Organised Crime and in the Judicial Reform COM (2014) 331.
} 
Durante $2013^{11}$ Albania finalizó los preparativos para la gestión descentralizada en el marco del Componente I. Para que la ejecución de los proyectos se realice en tiempo y forma es muy importante que el Gobierno albanés garantice la estabilidad de los funcionarios públicos formados para la gestión de los fondos del IAP y siga reforzando su formación.

Se han presentado dificultades en la ejecución de proyectos de infraestructura, debido a una falta de coordinación entre las instituciones implicadas tanto a nivel nacional como local. La falta de fondos nacionales para sufragar los costes de mantenimiento y explotación también ha producido retrasos en la ejecución y puede llegar a afectar a la continuidad de los proyectos a largo plazo.

La asignación indicativa de IAP II para Albania en el periodo 2014-2020 es de 640 millones de euros.

\section{Países candidatos potenciales}

El territorio de Kosovo se ha tratado ya en el punto de Serbia por no haber reconocido España su declaración unilateral de independencia. Por tanto, aquí sólo trataremos brevemente el caso de Bosnia y Herzegovina.

\subsection{Bosnia y Herzegovina}

El Estado de Bosnia y Herzegovina $(\mathrm{BiH})$ creado en el marco del Acuerdo de Paz de Dayton firmado el 14 de diciembre de 1995, está formado por dos entidades políticas dotadas de una amplia autonomía: la Federación de Bosnia y Herzegovina y la República Srpska, e incluye además el distrito autogobernado de Brcko. Fue considerado candidato potencial a la adhesión en la cumbre de Tesalónica de 2003.

\footnotetext{
${ }^{11}$ Informe anual de 2013 sobre la ayuda financiera para la ampliación (IAP, PHARE, CARDS, Instrumento de Preadhesión de Turquía, Mecanismo de Transición SWD(2014) 287 final.
}

El camino hacia la integración en la UE dio un paso importante el 26 de junio de 2008 con la firma del AEA y de su correspondiente Acuerdo interino sobre comercio y asuntos relacionados, que entró en vigor el 1 de julio de 2008 en espera de que terminara el proceso de ratificación del primero. El AEA ha sido ya ratificado pero no ha podido entrar en vigor por problemas de distinta índole.

Según el informe de 2013 sobre ayuda financiera preadhesión ${ }^{12}$, el país se hallaba en una situación de punto muerto en el proceso de integración europea debido a que no había respetado dos compromisos clave: la aplicación de la sentencia del Tribunal Europeo de Derechos Humanos en el asunto Sejdić-Finci ${ }^{13}$ y el establecimiento de un mecanismo de coordinación eficiente y eficaz que permitiera al país hablar con una sola voz ante la UE.

En su informe de progreso de $2014^{14}$ la Comisión constataba de nuevo la imposibilidad real de avance en las negociaciones y la necesidad urgente de que el país iniciara un diálogo constructivo con la UE. Existen además problemas técnicos relacionados con la ejecución de las reformas necesarias y con la adhesión de Croacia que dificultan el diálogo y la negociación.

Tras las duras críticas de la Comisión, en febrero de 2015 , la Presidencia de $\mathrm{BiH}$ ha acordado con la UE, mediante un compromiso escrito firmado por los líderes de los 14 partidos políticos presentes en el Parlamento, llevar a cabo las reformas políticas, sociales y económicas exigidas por la UE. Con ello ha desbloqueado su camino hacia la integración europea. El pasado 17 de marzo el Consejo de Ministros de Asuntos Exteriores de la UE ha dado luz verde a la conclusión y entrada en vigor del AEA.

\footnotetext{
12 Informe anual de 2013 sobre la ayuda financiera para la ampliación (IAP, PHARE, CARDS, Instrumento de Preadhesión de Turquía, Mecanismo de Transición SWD(2014) 287 final.

${ }^{13}$ De conformidad con la sentencia, Bosnia y Herzegovina debe garantizar el derecho a ser elegido para la Presidencia colectiva y para la Cámara de los Pueblos de la Asamblea Parlamentaria a todos los ciudadanos, independientemente de su origen étnico.

${ }^{14}$ Bosnia y Herzegovina Informe de Progreso $\{C O M(2014) 700$ final.
} 


\begin{tabular}{|c|c|c|c|}
\hline \multicolumn{4}{|c|}{$\begin{array}{c}\text { TABLA } 2 \\
\text { COMERCIO UE-PAÍSES CANDIDATOS } \\
\text { (En millones de euros) }\end{array}$} \\
\hline & 2009 & 2014 & \% Variación \\
\hline Export UE a países candidatos ............... & $60.520,41$ & $98.026,44$ & 61,97 \\
\hline Albania & $1.996,03$ & $2.470,88$ & 23,79 \\
\hline Bosnia y Herzegovina ................................ & $3.905,04$ & $5.025,82$ & 28,70 \\
\hline Kosovo (desde 01/06/2005) ...................... & 623,68 & 729,14 & 16,91 \\
\hline ARY Macedonia ….................................... & $2.159,23$ & $3.821,23$ & 76,97 \\
\hline Montenegro (desde 01/06/2005) ............... & 650,40 & 973,39 & 49,66 \\
\hline Serbia (desde 01/06/2005)........................... & $6.984,53$ & $10.374,02$ & 48,53 \\
\hline 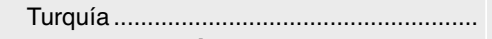 & $44.201,50$ & $74.631,98$ & 68,84 \\
\hline Import UE de países candidatos ............... & $43.987,13$ & $69.332,29$ & 57,62 \\
\hline 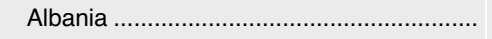 & 654,64 & $1.248,81$ & 90,76 \\
\hline Bosnia y Herzegovina ................................... & $1.933,57$ & $3.331,22$ & 72,28 \\
\hline Kosovo (desde 01/06/2005) ........................... & 78,63 & 95,62 & 21,61 \\
\hline 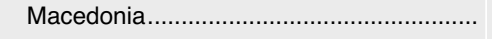 & $1.322,24$ & $3.025,07$ & 128,78 \\
\hline Montenegro (desde 01/06/2005) ................ & 171,63 & 249,14 & 45,16 \\
\hline Serbia (desde 01/06/2005)........................... & $3.410,88$ & $7.112,63$ & 108,53 \\
\hline Turquía ................................. & $36.415,55$ & $54.269,79$ & 49,03 \\
\hline 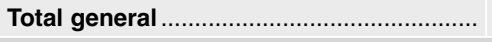 & $104.507,54$ & $167.358,74$ & 60,14 \\
\hline
\end{tabular}

\section{Asistencia financiera preadhesión}

El IAP asignó a BiH alrededor de 660 millones de euros para el periodo 2007-2013 y se aprobaron proyectos para las cantidades presupuestadas hasta 2012. En $2013^{15}$ la Comisión se manifestó contraria a seguir poniendo fondos preadhesión a disposición de países cuyos líderes políticos no estuvieran dispuestos a llegar a un consenso para que la ayuda diera los resultados esperados, lo que afectó a la programación y la ejecución de los fondos IAP.

La ausencia de mecanismos de coordinación y la creciente politización de la ejecución del IAP llevaron a la Comisión a suspender varios proyectos IAP durante 2013, reduciendo el presupuesto asignado para ese año de 109 a 64 millones de euros.

De momento, el IAP II sólo ha asignado fondos a BiH para el periodo 2014-2017 por un importe de 165,8 millones de euros. La Comisión decidió no comenzar la preparación de IAP II hasta que hubiera un mecanismo de coordinación efectivo y la definición de estrategias sectoriales.

15 Informe anual de 2013 sobre la ayuda financiera para la ampliación (IAP, PHARE, CARDS, Instrumento de Preadhesión de Turquía, Mecanismo de Transición SWD(2014) 287 final.

\section{Relaciones comerciales}

\section{Comercio UE con los países candidatos}

No hace falta decir que, de todos los países candidatos, Turquía es con diferencia el socio comercial más importante de la UE, siendo su cliente número 16 y su proveedor número 20. En 2014 Turquía importó de la UE principalmente máquinas y aparatos mecánicos (18 por 100), vehículos automóviles (13,2 por 100) y aparatos y material eléctrico (8 por 100) y exportó a la UE vehículos automóviles (19,7 por 100), máquinas y aparatos mecánicos $(10,7$ por 100) y prendas de vestir (10,5 por 100$)$.

El principal socio comercial de la UE en la región de los Balcanes Occidentales es Serbia, que ocupa el puesto 59 como cliente de la UE y el 69 como proveedor. En 2014 Serbia importó de la UE principalmente máquinas y aparatos mecánicos (13,8 por 100), combustibles (10 por 100) y aparatos y material eléctrico $(9,9$ por 100$)$ y exportó vehículos automóviles (18 por 100), aparatos y material eléctrico (10,7 por 100) y combustibles (6,7 por 100).

El resto de los países de la región están a una considerable distancia en cuanto a su posición como socios comerciales de la UE, situándose $\triangle$ 
en orden de importancia primero $\mathrm{BiH}$, seguida de ARY Macedonia, Albania y en último lugar Montenegro. Para todos los países, la UE es su principal socio comercial.

El proceso de asociación e integración europea, en todos los casos, ha supuesto un incremento de los flujos comerciales en ambos sentidos al haber liberalizado progresivamente el comercio en la mayoría de los ámbitos. Como referencia, observamos un incremento de las importaciones y exportaciones con este grupo de países en 2014 sobre 2009, superior al experimentado entre ambos años en el comercio de la UE con el resto del mundo, que fue del 39,8 por 100 en el total de sus exportaciones y del 35,1 por 100 en el total de sus importaciones.

En el año 2000 la UE concedió unilateralmente a los países de los Balcanes Occidentales unas preferencias comerciales que garantizaban un acceso ilimitado y libre de derechos al 95 por 100 de sus exportaciones a la UE, con el establecimiento de algunos contingentes arancelarios para determinados productos (vinos, carnes de ternera, algunos productos pesqueros y azúcar). Estas preferencias arancelarias autónomas se establecieron inicialmente por un período de 5 años, renovándose posteriormente en 2005 y 2010. Este año la Comisión está proponiendo una nueva prórroga de las mismas a partir del 1 de enero de 2016.

$\mathrm{BiH}$ es uno de los países beneficiarios de este régimen de preferencias arancelarias autónomas, cuya última prórroga expira el 31 de diciembre de 2015. Sin embargo, la Comisión ha propuesto suspender la aplicación a BiH de la nueva prórroga en tanto el país no adapte a la adhesión de Croacia los acuerdos existentes. Entre ellos, la adhesión de Croacia está afectando a la aplicación del Acuerdo interino ya que $\mathrm{BiH}$ no ha aceptado la metodología establecida para llevar a cabo la adaptación técnica de este Acuerdo que permita tener en cuenta su comercio bilateral tradicional con Croacia.

Los Acuerdos interinos sobre comercio y asuntos relacionados, firmados con cada uno de los países de los Balcanes Occidentales, han permitido la aplicación inmediata de la parte comercial de los AEA mientras se realizaba el proceso de ratificación de estos. Los Acuerdos interinos incluían una liberalización comercial asimétrica en favor de los países candidatos, tanto para productos industriales como agrícolas, reflejando el nivel de sensibilidad de los productos para los productores nacionales.

La entrada en vigor posterior de los AEA aumenta los beneficios económicos del Acuerdo interino mediante provisiones que contribuyen a mejorar el clima de negocios y que están relacionadas con la libre circulación de capitales, las compras públicas, la estandarización, los derechos de establecimiento, etcétera.

\section{Comercio de España con los países candidatos}

Como en el caso de la UE, para España los socios comerciales más importantes son, en primer lugar, Turquía seguida a mucha distancia por Serbia. Precisamente las exportaciones de España a Turquía entre 2009 y 2014 han ido creciendo de manera espectacular hasta alcanzar un porcentaje de variación del 93,16 por 100, que hace que el porcentaje de crecimiento de las exportaciones españolas a los países candidatos sea muy superior al porcentaje de crecimiento de las exportaciones de toda la UE. Los principales sectores de exportación española a Turquía en 2014 han sido vehículos automóviles (19,4 por 100), plásticos (7,8 por 100) y máquinas y aparatos mecánicos (7,7 por 100). Las importaciones españolas de Turquía sí han crecido de manera similar a las del resto de la UE, siendo los sectores principales de importación en 2014 prendas de vestir no punto (18,2 por 100), prendas de vestir punto $(16,1$ por 100$)$ y vehículos automóviles $(15,1$ por 100).

En la región de los Balcanes Occidentales, Serbia sigue siendo el principal socio comercial de España con un crecimiento importante de sus exportaciones a Serbia y moderado de las importaciones. Los $\square$ 


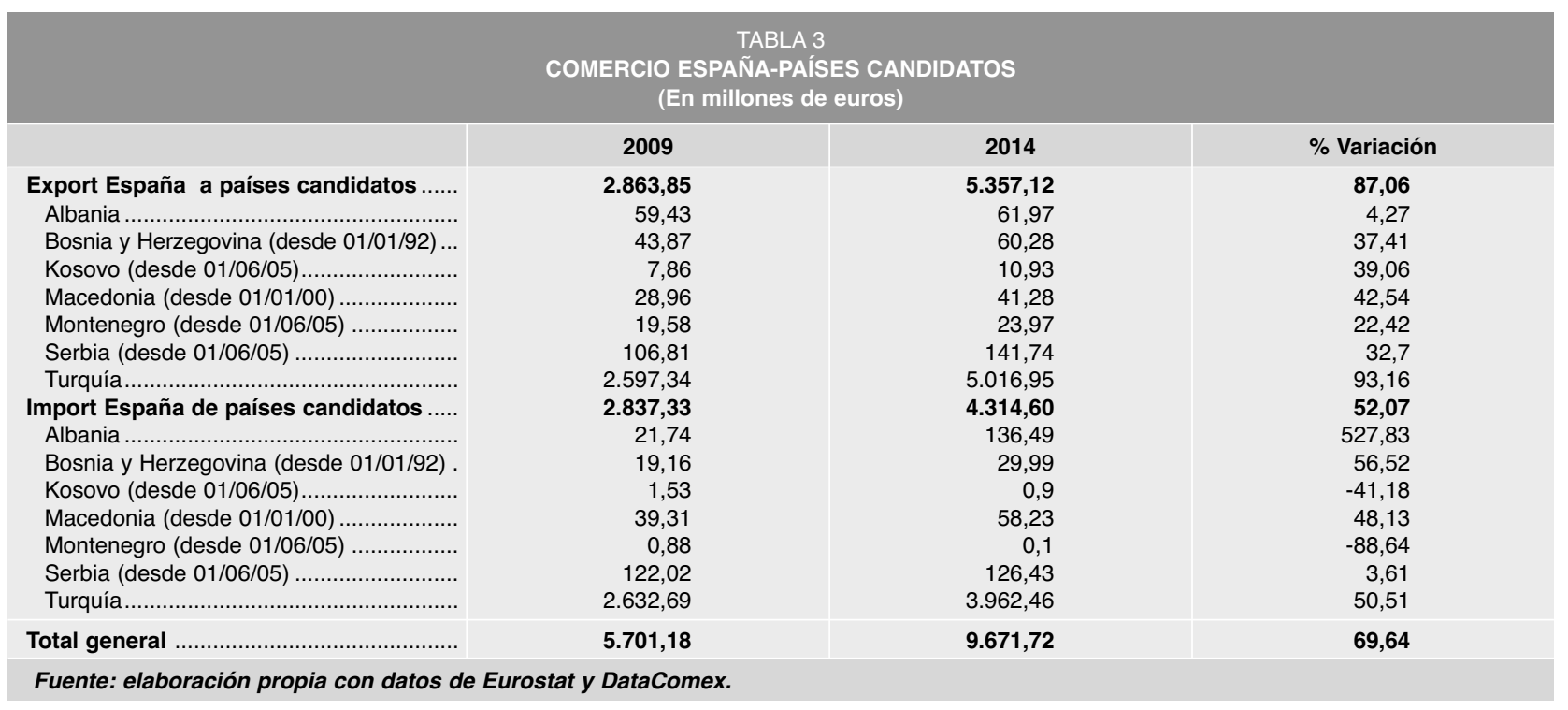

principales sectores de exportación a Serbia en 2014 han sido: carne (14 por 100), vehículos automóviles (10,9 por 100) y máquinas y aparatos mecánicos (7 por 100). Los principales sectores de importación han sido cereales (29,6 por 100), caucho y sus manufacturas $(29,1$ por 100$)$ y muebles (12,6 por 100).

El resto de los países están a una considerable distancia como socios comerciales de España. Es llamativo el caso de Albania porque las importaciones españolas de ese país han crecido hasta un 527 por 100 en 2014 respecto a 2009, aunque las cifras totales siguen siendo discretas. Los principales productos importados de Albania en 2014 han sido siderúrgicos $(54,7$ por 100$)$ y aparatos y material eléctrico $(29,6$ por 100$)$.

Como en el caso de la UE, el proceso de asociación y la creación de zonas de libre comercio han propiciado un incremento de los flujos comerciales en ambos sentidos en la mayoría de los casos. Los porcentajes de variación de 2014 sobre 2009 han sido superiores a los experimentados para los mismos años por las exportaciones españolas $(50,12$ por 100$)$ y las importaciones españolas $(28,32$ por 100$)$ con el resto del mundo.

\section{Conclusiones}

La integración europea contribuirá al desarrollo económico de los países candidatos, que es esencial no sólo para la estabilidad, prosperidad y seguridad de la región de los Balcanes Occidentales, sino también para la del conjunto de Europa.

El proceso de asociación e integración europea obliga a los países candidatos a cumplir unos requisitos políticos y económicos sin los cuales sería imposible su adhesión a la UE como miembros de pleno derecho. Para ello tienen que armonizar sus legislaciones nacionales con el acervo comunitario en todos los ámbitos.

Los Acuerdos de Asociación suponen una profundización de las relaciones económicas con la UE al no limitarse al establecimiento de concesiones comerciales e imponer obligaciones de armonización del mercado con las normas del mercado interior europeo.

El esquema progresivo de liberalización de sus mercados contemplado en estos Acuerdos prevé la aplicación de un régimen aduanero predecible, normas de competencia y ayudas de estado, así como de propiedad industrial e intelectual que ayudan a preparar paulatinamente a las empresas de los países candidatos para competir a largo plazo con las empresas comunitarias en el mercado interior.

Se pretende también mejorar el clima de negocios proporcionando un marco más claro y más seguro para inversores y empresas, lo que permitirá a estos países atraer mayor inversión exterior. 
Para las empresas españolas estos procesos de integración europea implican la oportunidad de abrir nuevos mercados para la exportación y muy especialmente para la inversión, ya que muchos de ellos tienen importantes atractivos como centro de producción.

El proceso de integración está plagado de escollos políticos y técnicos que retrasan considerablemente las negociaciones. Turquía tiene abiertas las negociaciones en varios capítulos pero están suspendidas en algunos por la cuestión chipriota. Las negociaciones con Serbia están cerca de abrirse pero la cuestión de Kosovo podría retrasar su marcha. Las negociaciones con ARY Macedonia están bloqueadas por Grecia mientras no se resuelva la cuestión del nombre.

Sólo las negociaciones con Montenegro avanzan a un paso razonable. Pero el anuncio que hizo el Presidente de la Comisión Europea, Jean-Claude Juncker, de que no contemplaba la adhesión de ningún Estado durante su mandato (2014-2019) muestra el camino de la UE en este terreno. 